Check for updates

Cite this: RSC Adv., 2017, 7, 49828

\title{
Preparation of hollow polyurethane microspheres with tunable surface structures via electrospraying technology
}

\begin{abstract}
Wuli Pu, Daihua Fu, Hesheng Xia and Zhanhua Wang (DD *
A facile one-step electrospraying technology was utilized to produce a novel kind of hollow polyurethane (PU) microspheres with controlled size and tunable surface morphology by adjusting the experiment parameters such as solvent, flow rate, applied voltage, and solution concentration. A porous-hollow structure can be obtained by increasing flow rate or solution concentration, or decreasing applied voltage. The decrease of flow rate or solution concentration, or the increase of applied voltage leads to hollow structures with a non-porous surface. The formation of porous-hollow morphology involves the PU polymer chains deposition during the solvent evaporation process and a phase separation phenomenon induced by the anti-solvent behavior in the water bath. The results demonstrate that the electrospraying method is a novel and facile method for preparing hollow polymer microspheres with tunable surface structures, and the obtained PU microspheres offer diversified applications ranging from adsorbents to drug delivery systems.
\end{abstract}

Received 4th September 2017 Accepted 18th October 2017

DOI: 10.1039/c7ra09831f

rsc.li/rsc-advances calcination or solvent etching. ${ }^{22,23}$ For example, Ge and coworkers reported “cage-like" polymer microspheres with a hollow core-porous shell structure by using a hard template technique. ${ }^{24}$ Wang et al. demonstrated a one-step emulsion method to prepare macroporous polymeric microspheres with multiple interconnected chambers. ${ }^{25}$ Some new methods such as solvent evaporation ${ }^{26}$ and microfluidics ${ }^{27}$ have also been successfully used for fabricating porous-hollow microspheres. However, those methods often require large amounts of solvent and multistep preparation procedures. Thus, developing a novel and facile method to prepare porous-hollow polymer microspheres are still highly desired.

Electrospraying is a method which applies high voltage to the conductive liquid at the needle tip to generate spray. The electrostatic force can overcome the surface tension and produce near-monodisperse droplets with diameters varying from tens of nanometers to hundreds of micrometers. ${ }^{28-31}$ The principle of electrospraying is essentially the same as that of electrospinning. However, the most obvious difference between electrospraying and electrospinning is the solution concentration used in the process as well as the chain entanglement density of the polymer solution. ${ }^{32}$ Higher solution concentrations tend to form continuous fibers as electrospinning process, while relatively lower concentrations will generate micro/ nanoparticles as electrospraying process. ${ }^{33}$ There are many outstanding features of the electrospraying. First, it is a onestep method without using lots of solvents and templates. Second, monodisperse droplets in micrometer/nanometer scale can be generated and the size is independent of the needle diameter. ${ }^{31}$ Third, the size distribution of the droplets is 
normally narrow, ${ }^{34}$ as well as the size and shape can be easily controlled by adjusting the experimental parameters. Regarding all of the advantages mentioned above, using electrospraying to fabricate hollow polyurethane microspheres with tunable surface structure come into our view.

In the previous studies, many polymer materials such as polylactide (PLA), ${ }^{35}$ poly(lactic-co-glycolic acid) (PLGA), ${ }^{36}$ polystyrene (PS), ${ }^{37}$ polycaprolactone (PCL), ${ }^{38}$ and chitosan ${ }^{39}$ were successfully employed to prepare solid, hollow, ${ }^{40}$ porous ${ }^{41}$ and core-shell ${ }^{28,42}$ microspheres by electrospraying. However, to the best of our knowledge, only a few studies about PU microspheres prepared by electrospraying were reported, ${ }^{43}$ and the hollow PU microspheres fabricated by electrospraying have never been reported yet. Herein, we show for the first time how to prepare the hollow PU microspheres with porous and non-porous surface structures using one-step electrospraying technique and investigate the key parameters of the electrospraying technique to control the size and morphology of microspheres. The PU was synthesized by using $4,4^{\prime}$-diphenylmethane diisocyanate (MDI) as the isocyanate, polycaprolactone diol (PCL-4000) as the diol, and 1,4-butanediol as the chain-extending agent. Gel permeation chromatography (GPC), Fourier transform infrared spectrometer (FTIR) and proton nuclear magnetic resonance spectrometer $\left({ }^{1} \mathrm{H}\right.$ NMR) were utilized for characterizations. The surface morphology and internal structure of PU microspheres were studied by scanning electron microscopy (SEM). The influence of solvent, collection bath, collecting distance, flow rate, applied voltage, and solution concentration on the size and morphology of PU microsphere were systematically studied. Finally, the formation mechanisms of hollow PU microspheres with two kinds of surface structures were proposed. The successful preparation of hollow PU microspheres via one-step electrospraying technology may provide a general method to fabricate hollow polymer microspheres with tunable surface structures. The obtained hollow PU microspheres with controlled porosity offer potential applications in many fields such as adsorbents, catalysis and drug delivery systems. Our work may provide a strategy towards the design and fabrication of various polymer microspheres in the future.

\section{Experimental}

\section{Materials}

Polycaprolactone diol (PCL, $M_{\mathrm{n}} \approx 4000 \mathrm{~g} \mathrm{~mol}^{-1}$, Pershorp, Capa 2402) was dried under vacuum at $110^{\circ} \mathrm{C}$ for $12 \mathrm{~h}$ prior to use. $4,4^{\prime}$ Diphenylmethane diisocyanate (MDI, $M_{\mathrm{n}}=250 \mathrm{~g} \mathrm{~mol}^{-1}$ ) was purchased from Yantai Wanhua Group. 1,4-Butylene glycol (BDO, $M_{\mathrm{n}}=90 \mathrm{~g} \mathrm{~mol}^{-1}$, Chengdu Kelong Chemical Co,. Ltd) was used as the chain extender agent. $N, N$-Dimethylformamide (DMF, $\geq 99.5 \%$, Chengdu Kelong Chemical Co,. Ltd) was distilled before use. Polysorbate 80 (Tween 80, Chengdu Kelong Chemical Co,. Ltd) was used as nonionic surfactants for the collection phase.

\section{Synthesis of linear polyurethane polymer}

The linear polyurethane polymer was synthesized according to Scheme 1. First, a precursor was synthesized by the reaction of
PCL and MDI $(1: 2)$ at $80^{\circ} \mathrm{C}$ under nitrogen atmosphere for $2 \mathrm{~h}$. The precursor ( $16.0 \mathrm{~g}, 3.55 \mathrm{mmol}$ ) and 1,4-butylene glycol (BDO) $(0.32 \mathrm{~g}, 3.55 \mathrm{mmol})$ were dissolved in anhydrous $N, N$-dimethylformamide (DMF, $90 \mathrm{~mL}$ ) and then stirred at room temperature for $24 \mathrm{~h}$. Eventually, $20 \mathrm{wt} \% \mathrm{PU}$ solution was obtained.

\section{Fabrication of porous-hollow PU microspheres}

The experimental setup is shown in Fig. 1. The preparation system consists of a mechanical syringe pump loaded with a syringe, a high voltage generator and a grounded collector. In the electrospraying process, the $20 \mathrm{wt} \%$ PU solution was placed into a $5 \mathrm{~mL}$ syringe and was continuously pushed by the syringe pump at a flow rate of $14 \mathrm{~mL} \mathrm{~h}^{-1}$ to a right angle bended stainless steel nozzle with an internal diameter of $0.5 \mathrm{~mm}$, which was connected to the high voltage power generator. The direct current high voltage generator was used to provide voltage of $8.5 \mathrm{kV}$ potential differences between the nozzle and the grounded collector. A collecting bath of deionized water with $0.5 \mathrm{wt} \%$ tween 80 as the surfactant was used as the ground collector. The spraying distance between the nozzle and the collector was maintained at $10 \mathrm{~cm}$. The obtained microspheres were washed with deionized water and centrifuged at $7000 \mathrm{rpm}$ for five times to remove the Tween 80 . At last, the microspheres were lyophilized using a freeze dryer.

\section{Fabrication of PU microspheres with different sizes and morphologies}

In order to fabricate PU microspheres with different sizes and morphologies, various electrospraying parameters that affect the formation of microspheres were investigated. To study the influence of solution concentration, different concentrations of PU solution ( $5 \mathrm{wt} \%, 10 \mathrm{wt} \%, 15 \mathrm{wt} \%$, and $20 \mathrm{wt} \%$ ) were used to prepare microspheres. Meanwhile, different flow rates $(3.5 \mathrm{~mL}$ $\mathrm{h}^{-1}, 7.0 \mathrm{~mL} \mathrm{~h}^{-1}, 10.5 \mathrm{~mL} \mathrm{~h}^{-1}, 14 \mathrm{~mL} \mathrm{~h}^{-1}$ and $17.5 \mathrm{~mL} \mathrm{~h}^{-1}$ ) and applied voltages $(8.5 \mathrm{kV}, 10.0 \mathrm{kV}, 11.5 \mathrm{kV}$ and $13.0 \mathrm{kV})$ to prepare microspheres were also studied, respectively. In addition, the influence of solvent, collection bath and collecting distance on the morphologies of PU microspheres was also investigated.

\section{Characterization}

The weight average molecular weight $\left(M_{\mathrm{w}}\right)$ of the synthesized PU was determined by gel permeation chromatography (GPC; HLC8320). For chemical structure analysis, PU was characterized by Fourier transform infrared spectrometer (FTIR; Nicolet 560) in the frequency range of $400-4000 \mathrm{~cm}^{-1}$, and the resolution and scanning number of FTIR test are $4 \mathrm{~cm}^{-1}$ and 32, respectively, and then further analyzed by using proton nuclear magnetic resonance spectrometer $\left({ }^{1} \mathrm{H}\right.$ NMR, Bruker ARX-400), operating at $400 \mathrm{MHz}$. Scanning electron microscopy (FEI, Quanta 250 field emission scanning electron microscope, SEM) was used to study the size and morphology of the fabricated PU microspheres. Before observation, the microspheres were dispersed in distilled water by ultrasonication and placed on a mica plate, then dried in a desiccator for $24 \mathrm{~h}$. The particle diameter and pore size of PU microspheres were determined by image 


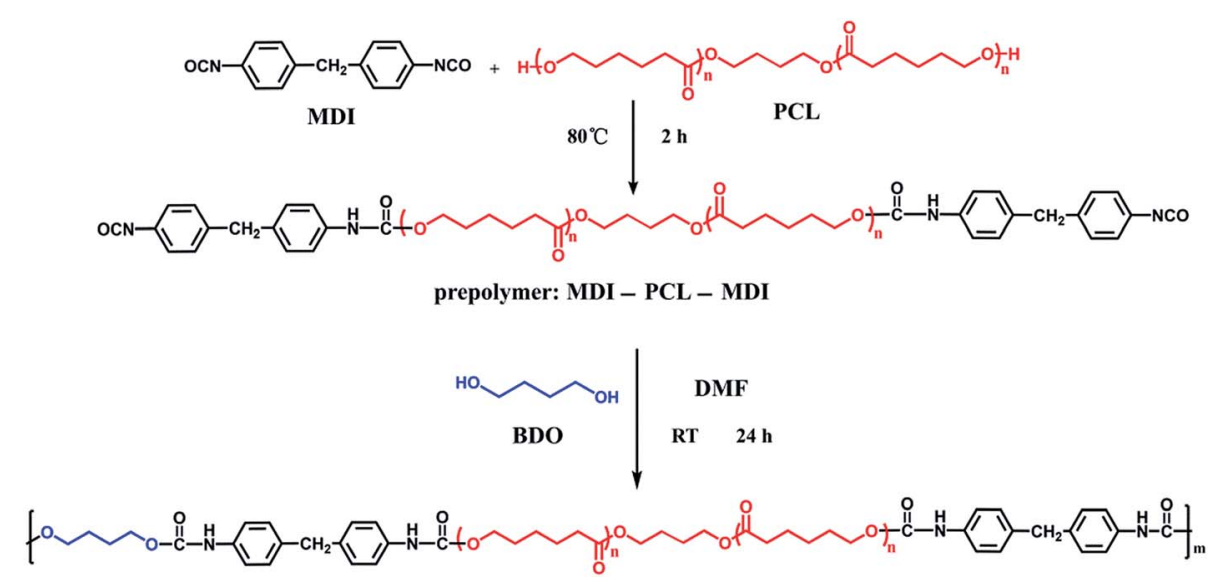

Scheme 1 Synthetic route of polyurethane.

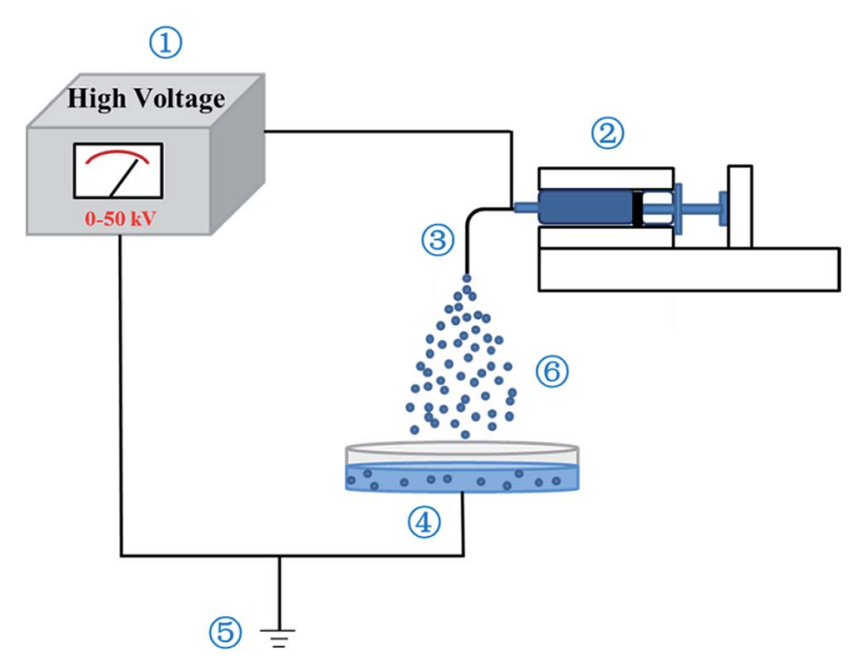

Fig. 1 Schematic diagram of electrospraying apparatus. (1) voltage generator; (2) injection; (3) needle; (4) collection bath; (5) grounding device; (6) spraying droplets.

analysis using Image-Pro Plus Software (Media Cybernetics). To investigate the internal nanostructures, the microsphere aqueous solution was frozen by liquid nitrogen, and then broken into powder by a hammer. The powder was lyophilized using a freeze dryer, and the cross-section morphology of the microspheres was observed using SEM.

\section{Results and discussion}

\section{Synthesis and characterization of PU}

We used a two-step polycondensation method to prepare PU, as shown in Scheme 1. FTIR was used to characterize the molecular structure of PU. As shown in Fig. 2a, the peaks at $\sim 1468 \mathrm{~cm}^{-1}, \sim 1534 \mathrm{~cm}^{-1}$ and $\sim 1602 \mathrm{~cm}^{-1}$ belong to the absorption of $\mathrm{C}-\mathrm{H}$ on the benzene ring. The peak at $\sim 1731 \mathrm{~cm}^{-1}$ is attributed to the absorption of carbamic acid ester groups. The peak of $\sim 3435 \mathrm{~cm}^{-1}$ can be assigned to the absorption of $\mathrm{N}-\mathrm{H}$. For the ${ }^{1} \mathrm{H}$ NMR spectroscopy study, as shown in Fig. 2b, the peaks at $9.48 \mathrm{ppm}$ and $8.52 \mathrm{ppm}$ belong to the carbamate group, and the peak at $3.78 \mathrm{ppm}$ belongs to the methine group in BDO. All of the above observations suggest the successful synthesis of the PU polymer. The results of GPC measurements show that the number average molecular weight $\left(M_{\mathrm{n}}\right)$, weight average molecular weight $\left(M_{\mathrm{w}}\right)$ and the polydispersity index (PDI) of the polyurethane are 29 575, 54836 and 1.85 , respectively.

\section{Characterization of PU microspheres prepared by electrospraying}

Fig. 3 are the SEM images of the PU microspheres fabricated by electrospraying. The microspheres were prepared from a $20 \mathrm{wt} \%$ PU solution with the following electrospraying parameters: the applied voltage is $8.5 \mathrm{kV}$ and the flow rate is $17.5 \mathrm{~mL} \mathrm{~h}^{-1}$, while the collecting distance is $10 \mathrm{~cm}$ and the collection bath is deionized water. According to the SEM images, the microspheres exhibit spherical morphologies with an average diameter of $\sim 29$ $\mu \mathrm{m}$ and a porous structure all over the surface. To investigate the internal structure, the cross-section of PU microspheres were observed, which displayed that the inner structure of $\mathrm{PU}$ microspheres is a hollow core with $\sim 23 \mu \mathrm{m}$ diameter in Fig. 3c and $\mathrm{d}$. The result indicates that a hollow core structure with a porous shell of PU microspheres could be generated by electrospraying without the assistance of any template.

\section{The influence of experiment parameters on the size and morphology of PU microspheres}

During the electrospraying process, the size and morphology of particles are controlled by electrospraying parameters, including solution physical properties such as surface tension, conductivity and viscosity, electrospraying distance, collection bath, strength of the electrostatic field, flow rate, and solution concentration. Some studies ${ }^{33,44}$ have investigated the influence of these electrospraying parameters on the size of polymer microspheres. However, these parameters also affect the solvent evaporation, which will further influence the morphology of PU microspheres. In order to obtain the PU microspheres with different sizes and morphologies, these parameters were investigated systematically in the following parts. 


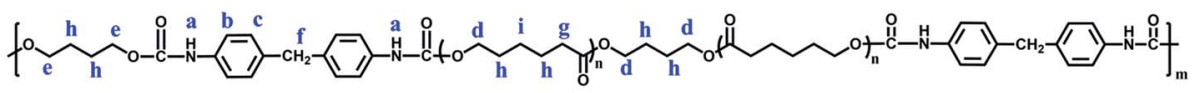

a

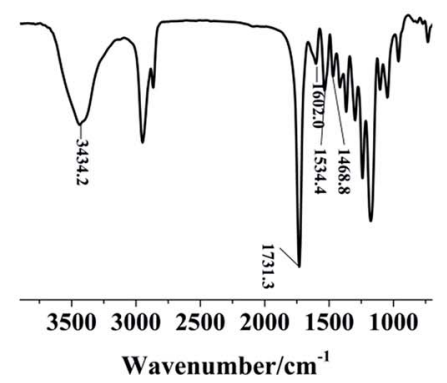

b

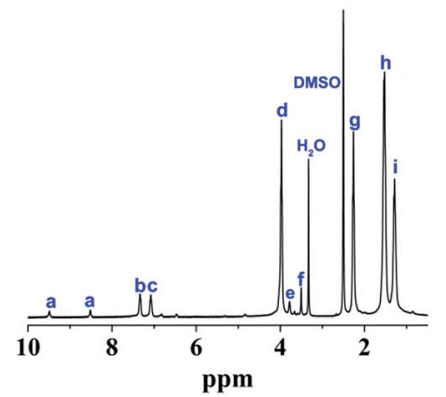

Fig. 2 FTIR spectra (a) and ${ }^{1} H$ NMR spectra (b) of the synthesized PU.
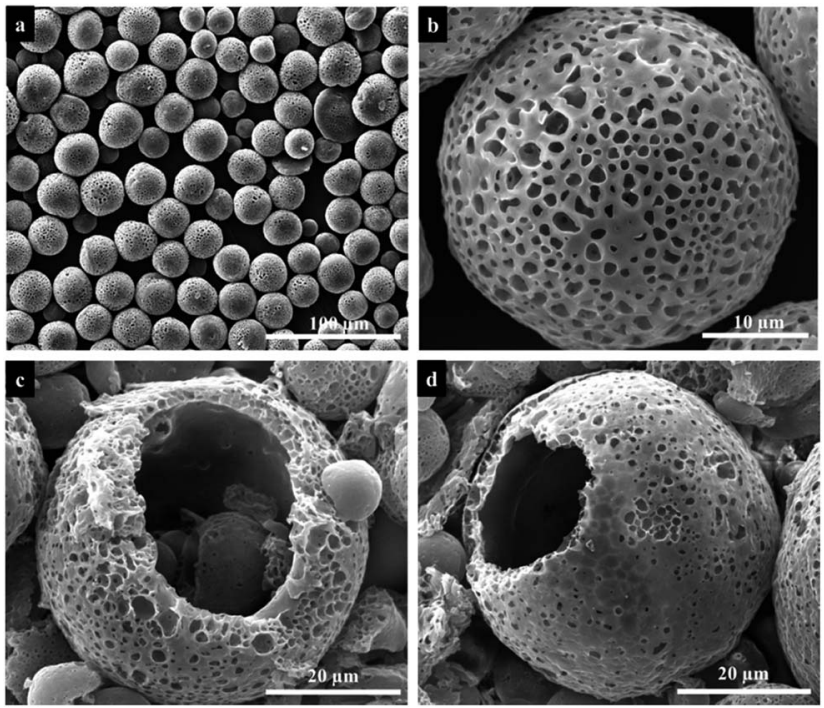

Fig. 3 Low (a) and high (b) magnification SEM images and crosssection SEM images $(c, d)$ of the obtained PU microspheres fabricated by electrospraying.

Effect of solvent. The preparation of PU microspheres using electrospraying method displayed a great dependence on the solvent properties. To investigate the influence of solvent on the morphology of PU microspheres, we chose three different kinds of solvents to prepare a series of PU microspheres. Under the conditions of applied voltage of $8.5 \mathrm{kV}$, solution concentration of $20 \mathrm{wt} \%$, flow rate at $14 \mathrm{~mL} \mathrm{~h}^{-1}$ and deionized water as the collection bath, we prepared PU microspheres with $N, N$ dimethyl formamide (DMF) and tetrahydrofuran (THF) as the solvent, respectively. As shown in Fig. 4a and b, when DMF was used as solvent, the porous and uniform microspheres were obtained. However, using THF as solvent can only generate the monodisperse solid microspheres with wrinkle surface. As for DCM, the solubility of PU in DCM is much lower than that in DMF and THF. So we prepared $5 \mathrm{wt} \%$ PU solution and kept other electrospraying parameters the same as before. When the collection bath is changed from deionized water to ethanol, we could get some particles. As is shown in Fig. 4c, the morphology of the particles is irregular and the size is not uniform. What's more, most particles are collapsed and have a rough surface. The properties of three solvents including dielectric constant and boiling point are listed in Table 1. In general, the conductivity of a solution is determined by the polymer and the solvent. As previously reported, an increased conductivity of a solution implies that more charge is carried by the electrospraying jet. Under the same polymer concentration, larger particles can be prepared using a solvent with a lower dielectric constant. ${ }^{36}$ Therefore, we obtained slightly bigger PU microspheres in THF and DCM than using DMF as the solvent. On the other hand, the boiling point of THF is much lower than DMF, which means the evaporation rate of THF is faster during electrospraying process. As a result, the PU polymer chains solidify rapidly and result in a wrinkle surface. DCM has an even lower boiling point than THF. The too fast evaporation rate will cause the asymmetrical and rapid precipitation of PU polymer chains, leading to the collapse of particles and the generation of fragmented particles. That's why the irregular particles were obtained. So it is clear that the solvent properties have a great influence on the morphology and diameter of PU microspheres.

Effect of collection bath. In some reports, the particles were electrojetted on a substrate. However, the particles prepared by this method are likely to collapse when the solvent does not evaporate completely before particles drop onto the substrate. Herein, we used different kinds of liquid as collection bath, and found that it would affect the phase separation process and further the morphology of particles. Under the conditions of the applied voltage at $8.5 \mathrm{kV}$, the solution concentration at $20 \mathrm{wt} \%$, the flow rate at $14 \mathrm{~mL} \mathrm{~h}^{-1}$ and DMF as the solvent, PU microspheres were prepared by electrospraying using deionized water and ethanol as collection bath, respectively. As shown in Fig. 5a, when using deionized water as the collection bath, the microspheres are spherical with a porous surface and have a uniform particle size. However, the PU microspheres prepared with ethanol as the collection bath have a smooth surface. In addition, most parts of the surface are damaged, and adhesion phenomenon is serious (Fig. 5b). This phenomenon may result from the different liquid-liquid phase separation process of $\mathrm{DMF} / \mathrm{PU}$ solution in deionized water and in ethanol. It indicates that selecting the appropriate collecting bath is a key factor to obtain regular polymer microspheres. 

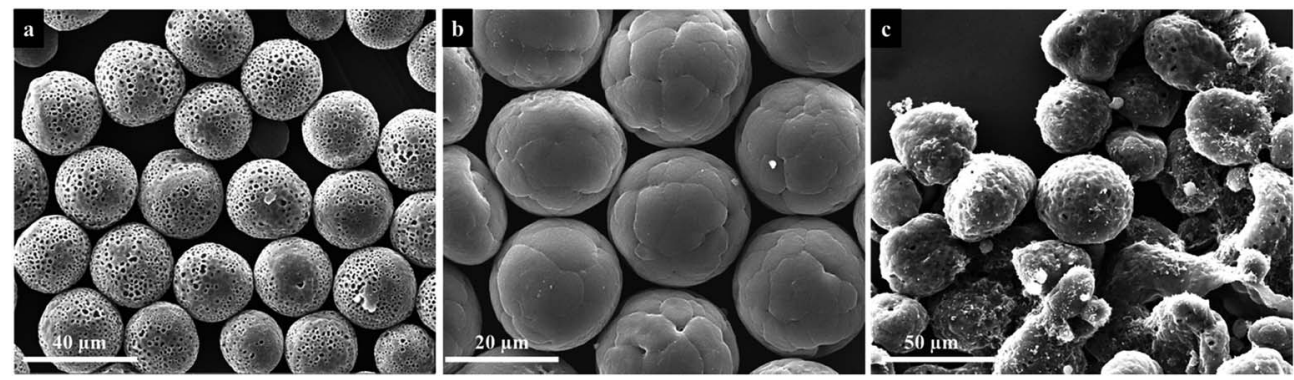

Fig. 4 SEM images of PU microspheres prepared with different solvents: (a) DMF; (b) THF ((a and b), deionized water as the collection bath); (c) DCM (ethanol as the collection bath) (voltage: $8.5 \mathrm{kV}$; solution concentration: $20 \mathrm{wt} \%$; flow rate: $14 \mathrm{~mL} \mathrm{~h}^{-1}$ and collecting distance: $10 \mathrm{~cm}$ ).

Table 1 The dielectric constant and boiling point of DMF, THF and DCM

\begin{tabular}{lll}
\hline Solvent & $\begin{array}{l}\text { Dielectric constant } \\
\left(\text { at } 20{ }^{\circ} \mathrm{C}\right)\end{array}$ & $\begin{array}{l}\text { Boiling point } \\
\left({ }^{\circ} \mathrm{C}\right)\end{array}$ \\
\hline DMF & 37.6 & 152.8 \\
THF & 7.52 & 66 \\
DCM & 8.9 & 39.8 \\
\hline
\end{tabular}

Effect of collecting distance. The collecting distance between the needle tip and the collection device will influence the strength of the electric field and the solvent evaporation during electrospraying process, which may further affect the microsphere size and morphology. ${ }^{44-46}$ Fig. 6 shows that the surface morphology of the PU microspheres changed from porous to non-porous when increasing collecting distance from $10 \mathrm{~cm}$ to $25 \mathrm{~cm}$. Microspheres with some small holes on the surface were obtained when the collecting distance of $10 \mathrm{~cm}$ was applied. With the increase of collecting distance, the number of holes deceased and eventually a closed surface was obtained. This may attribute to the change of the solvent evaporation rate during the electrospraying process when the collecting distance varies. When the needle tip is closer to the collector, the solvent does not evaporate completely before the droplets get into the collection bath, which leads to phase separation because of the liquid-liquid exchange between the water and the solvent. When the collecting distance increases, the solvent evaporates more thoroughly. So, the phase separation in collection bath alleviates and fewer pores are formed and even disappeared when the collecting distance is far enough. It must be pointed out that when the distance between the collection bath and the needle tip is too short, there will be an unstable electrospraying process. As a result, when using DMF as the solvent, deionized water as the collection bath and the collecting distance is $10 \mathrm{~cm}$, we can obtain the regular PU microspheres. So, we chose these parameters for the rest of the study unless specified.

Effect of flow rate. Under the condition of the solution concentration of $20 \mathrm{wt} \%$, the applied voltage of $8.5 \mathrm{kV}$ and DMF as the solvent, we prepared different $\mathrm{PU}$ microspheres with the flow rate at $3.5 \mathrm{~mL} \mathrm{~h}^{-1}, 7.0 \mathrm{~mL} \mathrm{~h}^{-1}, 10.5 \mathrm{~mL} \mathrm{~h}^{-1}, 14 \mathrm{~mL} \mathrm{~h}^{-1}$ and $17.5 \mathrm{~mL} \mathrm{~h}^{-1}$, respectively. The SEM images and the average particle size histograms of PU microspheres at different flow rates are shown in Fig. 7. When the flow rate increases from $3.5 \mathrm{~mL} \mathrm{~h}^{-1}$ to $17.5 \mathrm{~mL} \mathrm{~h}^{-1}$, the average particle size of $\mathrm{PU}$ microspheres increases from $8.7 \mu \mathrm{m}$ to $29.4 \mu \mathrm{m}$. This is probably because when a certain voltage is applied, the generated electric field force is sufficient to cause the jet disperses more evenly and thoroughly under a slower flow rate. So, the jet can split into many smaller droplets, resulting in microspheres with smaller average particle size. With the increase of flow rate, the electric field strength in a short period of time is not enough to make jet stream split into smaller droplets, so the larger microspheres is obtained. As for the morphology of microspheres, we can see from the Fig. 7a-e clearly that with the
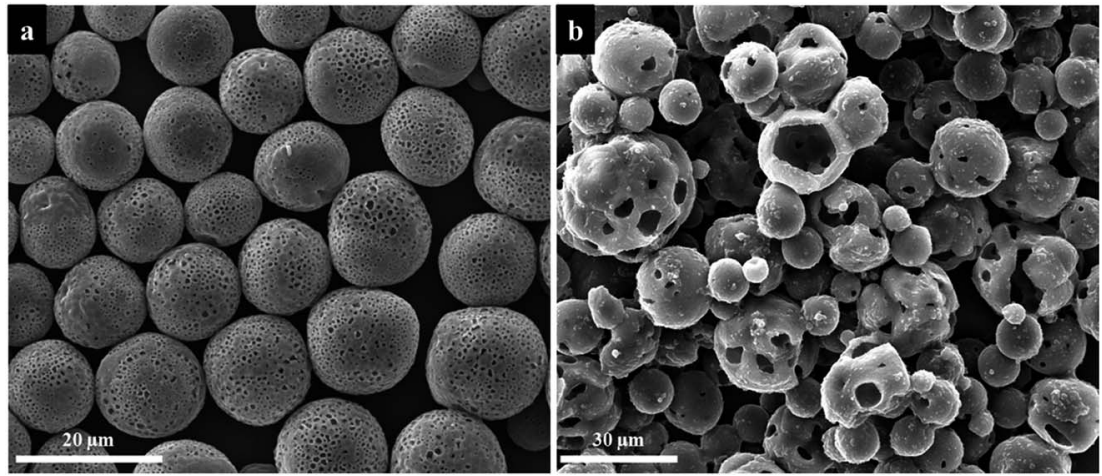

Fig. 5 SEM images of PU microspheres fabricated with different collection baths: (a) deionized water; (b) ethanol (voltage: $8.5 \mathrm{kV}$; solution concentration: $20 \mathrm{wt} \%$; flow rate: $14 \mathrm{~mL} \mathrm{~h}^{-1}$ and collecting distance: $10 \mathrm{~cm}$ ). 

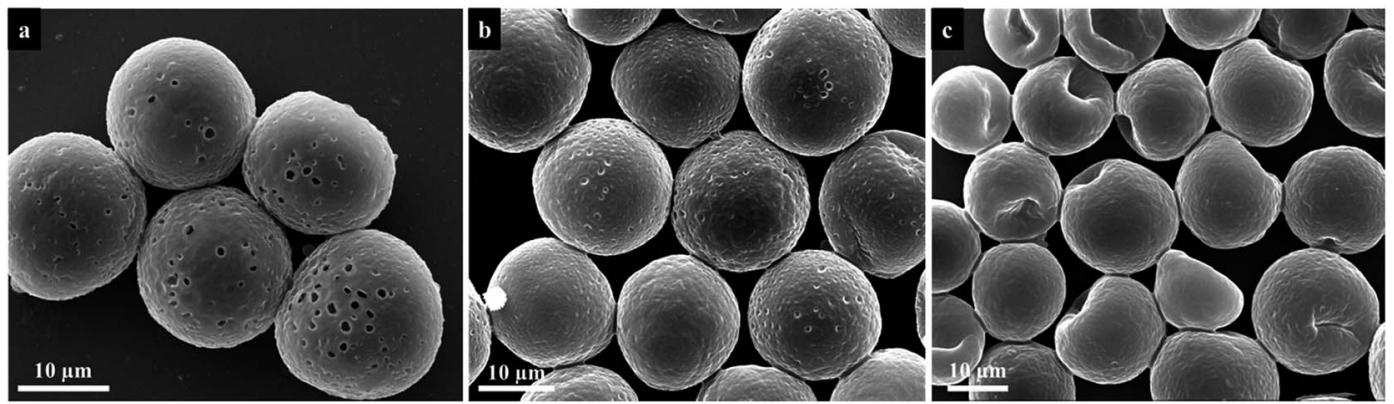

Fig. 6 SEM images of PU microspheres fabricated with different collecting distances: (a) $10 \mathrm{~cm}$; (b) $18 \mathrm{~cm}$; (c) $25 \mathrm{~cm}$ (voltage: $8.5 \mathrm{kV}$; solution concentration: $20 \mathrm{wt} \%$; and flow rate: $10.5 \mathrm{~mL} \mathrm{~h}^{-1}$ ).
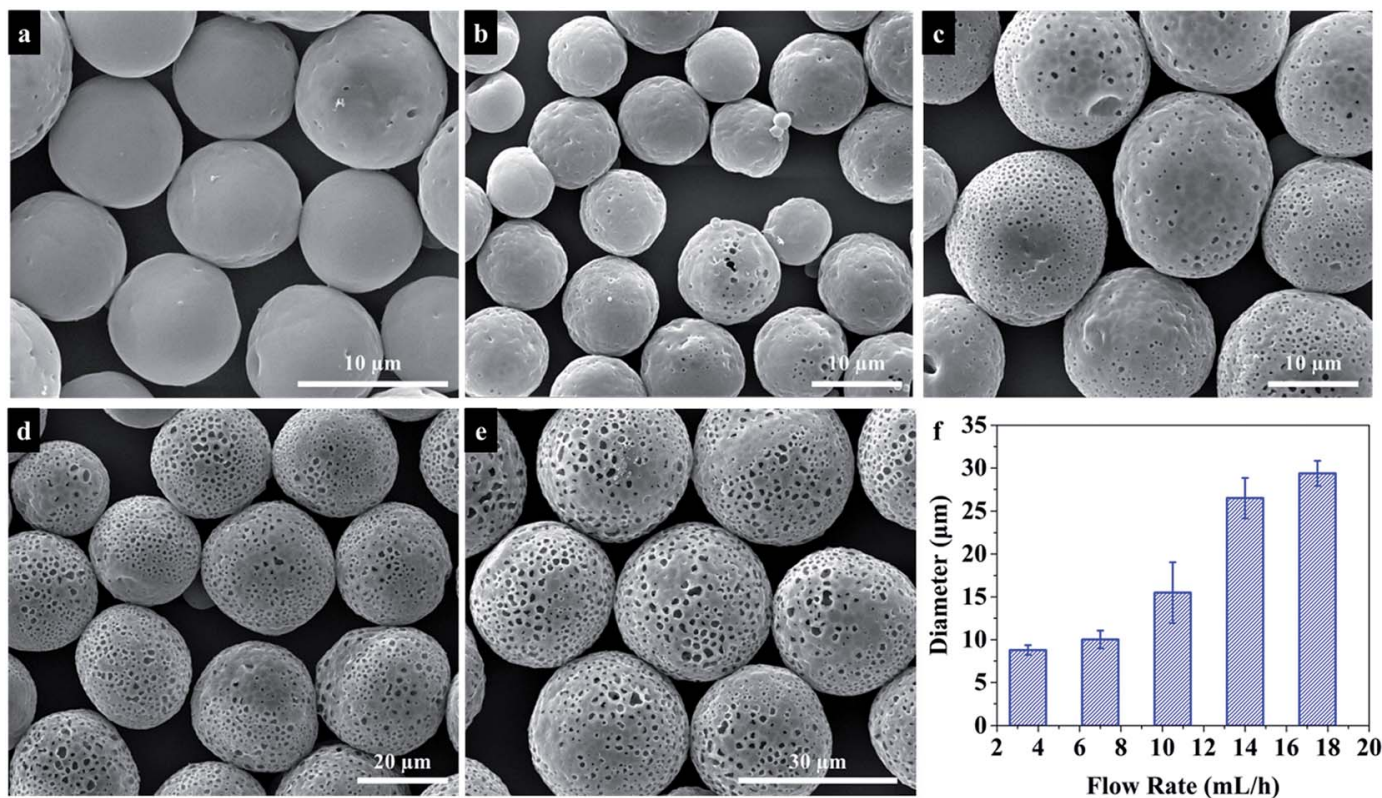

Fig. 7 SEM images of PU microspheres prepared with different flow rates: (a) $3.5 \mathrm{~mL} \mathrm{~h}^{-1}$, (b) $7.0 \mathrm{~mL} \mathrm{~h}^{-1}$, (c) $10.5 \mathrm{~mL} \mathrm{~h}{ }^{-1}$, (d) $14 \mathrm{~mL} \mathrm{~h}-1$, (e) $17.5 \mathrm{~mL}$ $\mathrm{h}^{-1}$. (f) The particle size of PU microspheres with different flow rates (voltage: $8.5 \mathrm{kV}$; solution concentration: 20 wt\%; and collecting distance: $10 \mathrm{~cm})$.

increase of flow rate, the non-porous surface of PU microspheres gradually transforms into a porous structure. The higher the flow rate is, the larger the holes on the surface of the microspheres can be obtained. As shown in Fig. 8, when the flow rate increases from $3.5 \mathrm{~mL} \mathrm{~h}^{-1}$ to $17.5 \mathrm{~mL} \mathrm{~h}^{-1}$, the particle size of PU microspheres increases significantly and microspheres morphology changes from smooth non-porous surface into porous surface. This behavior is probably due to the different evaporation rate of DMF at different flow rates. Faster flow rate induces a slower solvent evaporation rate, which will induce phase separation in the collection bath, resulting in bigger particles with more porous structures.

Effect of applied voltage. Fig. 9e shows the average particle size histogram of polyurethane microspheres fabricated at different applied voltages. As shown in this histogram, keeping other conditions (flow rate, solution concentration, etc.) constant, increasing the applied voltage will reduce the size of PU microspheres. When the applied voltage rises from $8.5 \mathrm{kV}$ to
$13 \mathrm{kV}$, the average particle size decreases from $26.5 \mu \mathrm{m}$ to 8.3 $\mu \mathrm{m}$. In the electrospraying process, when the applied voltage is changed, the electric field force exerted on the injection fluid will be altered. The liquid particles are directly resulted from the dispersion of Taylor cone which is formed because the electric field force overcomes the surface tension. When the voltage increases, the electrostatic force with respect to the surface tension increases, then the formation of jet flow will be more scattered. Therefore, changing the applied voltage can play a regulatory role in adjusting the microspheres particle size theoretically. The morphology of PU microspheres with different applied voltages are shown in Fig. 9a-d. With the increase of applied voltage, the holes on the surface of PU microspheres gradually reduce, and eventually the porous surface transforms into a non-porous structure when the applied voltage increases to $13 \mathrm{kV}$. The essence of this phenomenon is the same as the change of flow rate. Both the increase of flow rate and the decrease of applied voltage will 

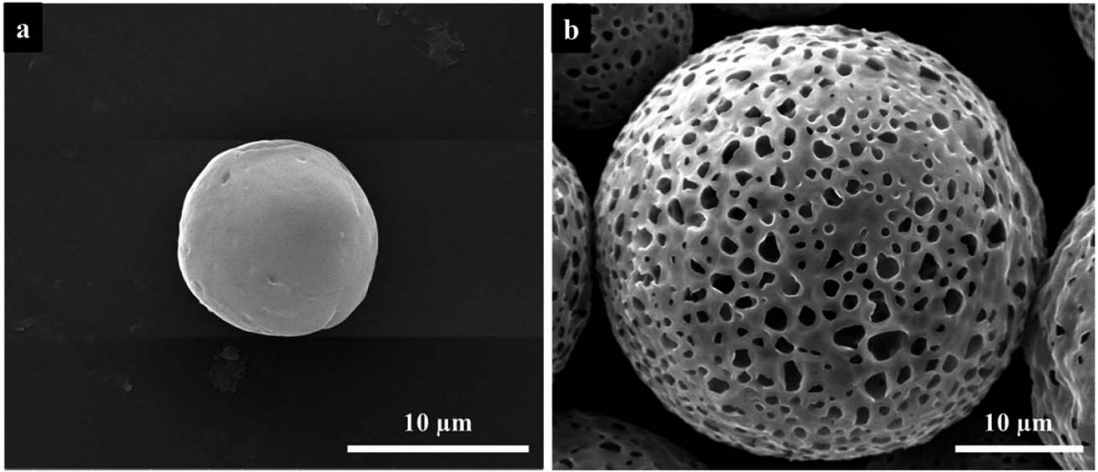

Fig. 8 High magnification SEM images of PU microspheres prepared with different flow rates: (a) $3.5 \mathrm{~mL} \mathrm{~h}^{-1}$; (b) $17.5 \mathrm{~mL} \mathrm{~h}$ (voltage: $8.5 \mathrm{kV}$; solution concentration: 20 wt\%; and collecting distance: $10 \mathrm{~cm}$ ).
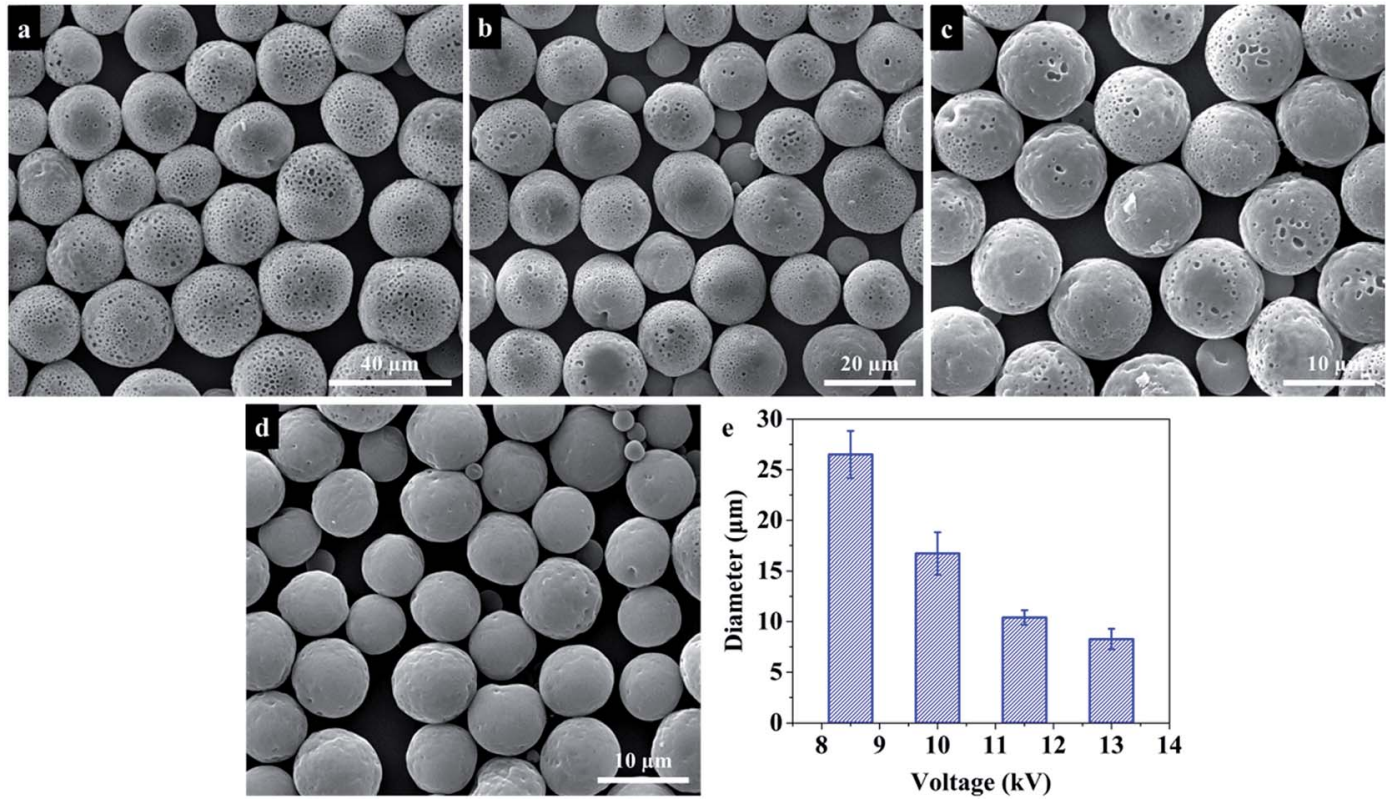

Fig. 9 SEM images of PU microspheres produced with different applied voltages: (a) $8.5 \mathrm{kV}$, (b) $10.0 \mathrm{kV}$, (c) $11.5 \mathrm{kV}$, (d) $13.0 \mathrm{kV}$ and (e) the particle size of PU microspheres with different applied voltages (flow rate: $14 \mathrm{~mL} \mathrm{~h}^{-1}$; solution concentration: 20 wt\%; and collecting distance: $10 \mathrm{~cm}$ ).

generate larger PU particles. And as shown in Fig. 9, when the particles are large enough, the porous PU microspheres with many holes on the surface are obtained. This is because there is insufficient time for DMF to evaporate completely before the particles drop into the collection bath.

Effect of solution concentration. The influence of polymer solution concentration on the PU microspheres is complicated. As shown in Fig. 10e, the average particle size of PU microspheres increases with the increase of solution concentration. When the concentration of PU solution rises from $5 \mathrm{wt} \%$ to $20 \mathrm{wt} \%$, the average particle size of PU microspheres increases from $4.5 \mu \mathrm{m}$ to $15.5 \mu \mathrm{m}$. What's more, as shown in SEM images of Fig. 10a-d, the PU microspheres are porous and spherical within a narrow range of size distribution at $20 \mathrm{wt} \% \mathrm{PU}$ concentration. For PU concentration below $20 \mathrm{wt} \%$, the PU microspheres with non-porous surface and relatively irregular shapes were obtained. At $5 \mathrm{wt} \%$ solution concentration, the microspheres are interconnected with each other. This is because that different solution concentration will lead to a change in the surface tension and viscosity, which will affect the entanglement of polymer molecular chains in the electrospraying droplets, further influence the morphology and size of polymer microspheres. ${ }^{35}$ With the decrease of solution concentration, the viscosity and the entanglement of polymer molecular chains with each other decrease. This means the PU molecular chains can move easily and the droplets will deform during the DMF evaporation process, which results in irregular particles. So, only at appropriate solution concentration, the microspheres with spherical shape can be fabricated.

\section{The internal structure of PU microspheres}

In above studies, we have discussed the influence of different electrospraying parameters on the size and surface morphology of PU microspheres. Now the factors to affect the internal 

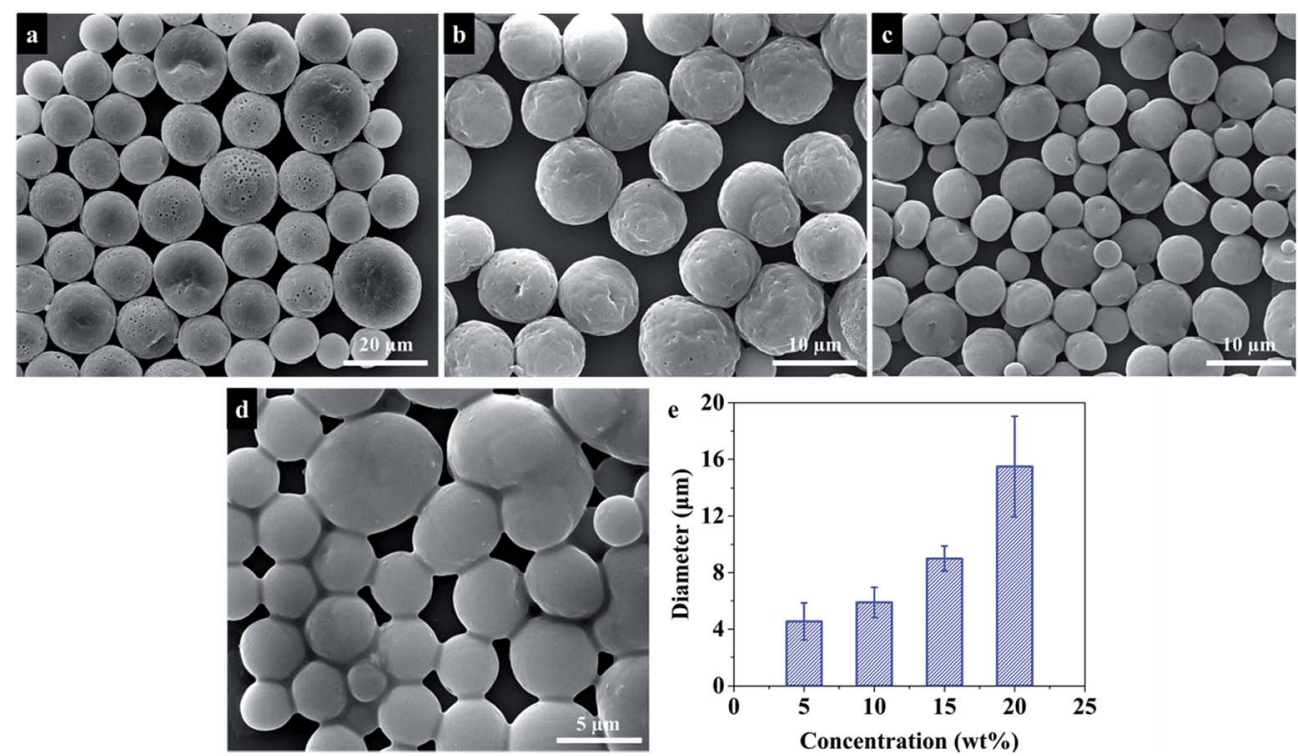

Fig. 10 SEM images of PU microspheres fabricated with different solution concentrations: (a) 20 wt\%, (b) 15 wt $\%$, (c) 10 wt\%, (d) 5 wt $\%$ and (e) the particle size of PU microspheres with different solution concentrations (voltage: $8.5 \mathrm{kV}$; flow rate: $10.5 \mathrm{~mL} \mathrm{~h}^{-1}$; and collecting distance: $10 \mathrm{~cm}$ ).

structure of PU microspheres are investigated. By changing the flow rate when other parameters remained the same, PU microspheres with porous surface and smooth non-porous surface can be obtained as shown in Fig. 7. Fig. 11 shows the cross-section images of PU microspheres with different sizes and surface morphologies. To our surprise, the smallest microspheres with non-porous surface also have a hollow structure. When the non-porous surface of PU microspheres gradually transforms into a porous structure, the hollow internal structure always remains. Other electrospraying parameters, such as applied voltage and solution concentration, essentially influence the size of liquid particles sprayed from the Taylor cone, but not the formation process of the microspheres. Therefore, we can speculate that when using DMF as solvent, deionized water as the collection bath and the collecting distance is $10 \mathrm{~cm}$, the smaller PU microspheres have hollow internal structure with non-porous surface, while the bigger PU microspheres have hollow internal structure with porous surface. Therefore, we can get the conclusion that hollow polyurethane microspheres with tunable surface structure were successfully prepared without any template by electrospraying.
The possible formation mechanisms of hollow PU microspheres with porous and non-porous surface

According to the above results, we proposed the diffusion deposition-phase separation mechanism to explain the evolution process of the hollow PU microspheres with two different surface structures. The possible formation mechanisms are shown in Fig. 12. When the PU-DMF solution fragments to microdroplets, the surface of droplets is solidified due to the rapid solvent evaporation in the air. The PU segments inside the microdroplets continue to move to the surface and precipitate during the process of dropping from the needle tip to the collection bath, resulting in a hollow structure inside particles. Because the droplets are very small, most of the DMF solvent evaporates before the particles drop into the water bath, which attributes to the hollow microspheres with non-porous surface (Fig. 12A). The formation process of porous-hollow microspheres can be divided into two steps (Fig. 12B). The first step is rapid evaporation of DMF solvent and precipitation of $\mathrm{PU}$ segments as same as the formation process of hollow PU microspheres. With the increase of electrospraying flow rate or solution concentration, or the decrease of applied voltage, the
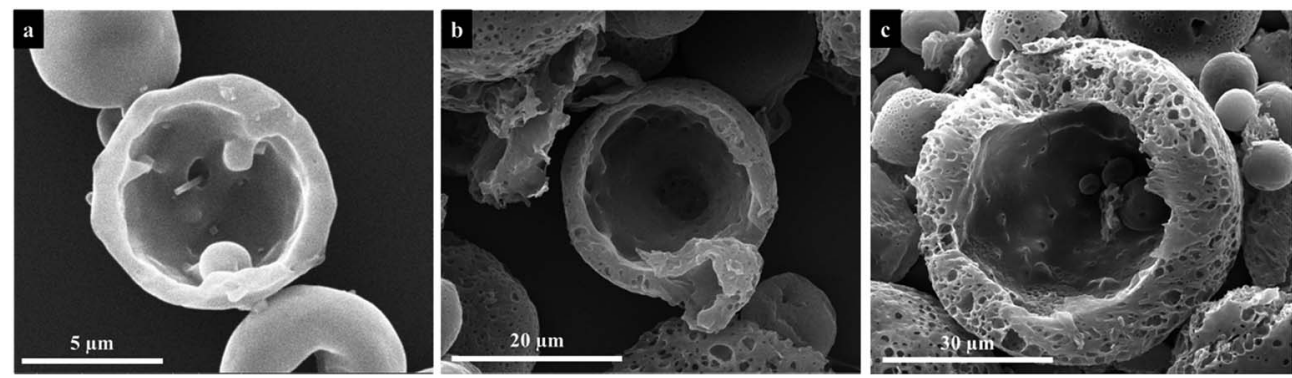

Fig. 11 Cross-section SEM images of the PU microspheres produced with different flow rates: (a) $3.5 \mathrm{~mL} \mathrm{~h}^{-1}$, (b) $10.5 \mathrm{~mL} \mathrm{~h}{ }^{-1}$, (c) $17.5 \mathrm{~mL} \mathrm{~h}^{-1}$ (voltage: $8.5 \mathrm{kV}$; solution concentration: $20 \mathrm{wt} \%$; and collecting distance: $10 \mathrm{~cm}$ ). 


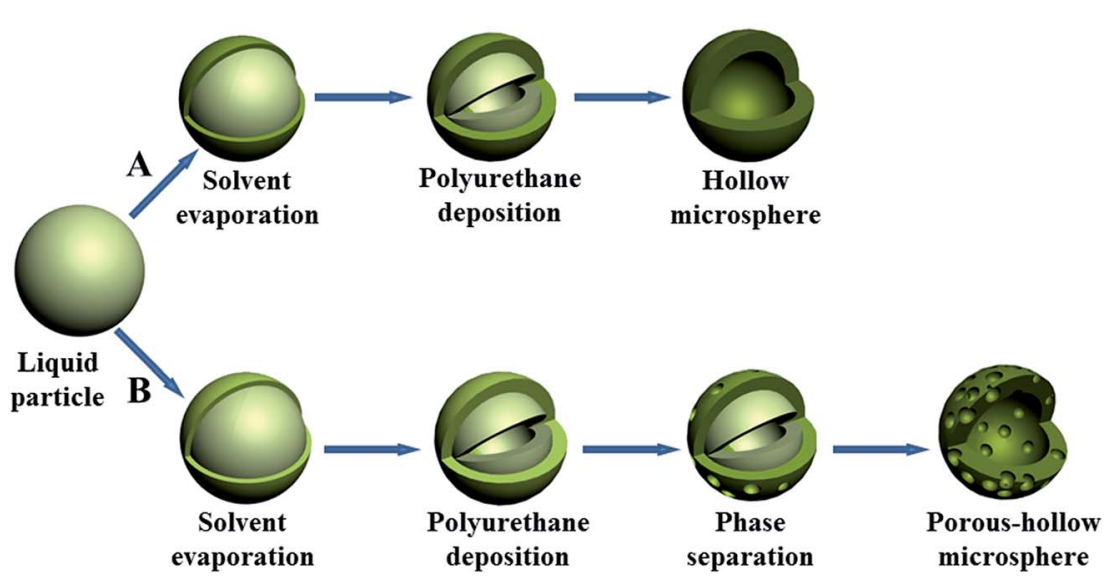

Fig. 12 Schematic illustration of the two different kinds of PU microspheres formation mechanisms: (A) hollow microspheres with smaller size and $(\mathrm{B})$ porous-hollow microspheres with bigger size.

diameter of microdroplets become bigger and the solvent evaporates incompletely before the particles drop into the collection bath. As water displays high solubility for DMF but it is anti-solvent for PU, When the PU/DMF particles drop into water, liquid-liquid phase separation occurs during rapid exchange of the DMF and water. After the completion of the exchange, the porous shell is formed. Eventually, the poroushollow microspheres are obtained. The diffusion depositionphase separation mechanism suggests that electrospraying technology also may be used in preparing other porous-hollow polymer microspheres. Compared with conventional methods such as template technique, ${ }^{24}$ double emulsion technique ${ }^{47}$ and coaxial electrospraying, ${ }^{40}$ electrospraying technology is a simple one-step method to prepare porous-hollow microspheres without other external assistant, and can easily tune the surface morphology of microspheres.

\section{Conclusions}

In conclusion, we have developed a novel one-step electrospraying technology to fabricate hollow PU microspheres with different surface structures. Their sizes and morphologies can be tuned by changing the electrospraying parameters, such as solvent, solution concentration, collection bath, flow rate and applied voltage. Two different kinds of PU microspheres with hollow structures can be obtained via adjusting the electrospraying parameters. A porous-hollow structure can be obtained by increasing flow rate or solution concentration, or decreasing applied voltage. The decrease of flow rate or solution concentration, or the increase of applied voltage leads to hollow structure with a non-porous surface. When the size of liquid droplets is bigger enough, the solvent does not evaporate completely before the particles drop into the collecting bath. The anti-solvent behavior generated in this process induces phase separation and causes a porous surface. While for smaller droplets, the solvent evaporates very fast and completely during the deposition process and leads to a non-porous surface. This work provides a general method to fabricate hollow polymer microspheres with tunable surface structures. The obtained hollow PU microspheres offer potential applications in many fields such as adsorbents, catalysis and drug delivery systems.

\section{Conflicts of interest}

There are no conflicts to declare.

\section{Acknowledgements}

This project was financially supported by the National Science Foundation of China (NSFC) under Grant No. 51703143 and the State Key Laboratory of Polymer Materials Engineering (Grant No. sklpme2017-3-04), and the starting fund of Sichuan University (Grant No. 20822041A4195).

\section{Notes and references}

1 G. Oertel and L. Abele, Polyurethane handbook: chemistry, raw materials, processing, application, properties, Hanser Publishers. Distributed in USA by Scientific and Technical Books, Macmillan, 1985.

2 H.-W. Engels, H.-G. Pirkl, R. Albers, R. W. Albach, J. Krause, A. Hoffmann, H. Casselmann and J. Dormish, Angew. Chem., Int. Ed., 2013, 52, 9422-9441.

3 L. Zhang, L. Chen and S. J. Rowan, Macromol. Chem. Phys., 2017, 218, 1600320.

4 P. V. Siva Reddy, G. N. Mahesh, S. Ramesh, P. A. Sivakumar and G. Radhakrishnan, J. Macromol. Sci., Part A: Pure Appl.Chem., 1995, 32, 789-799.

5 C.-Y. Lin and S.-h. Hsu, J. Biomed. Mater. Res., Part B, 2015, 103, 878-887.

6 M. Li and J. Xue, Langmuir, 2011, 27, 3229-3232.

7 S. Budriene, T. Romaskevic, K. Pielichowski and J. Pielichowski, Polym. Adv. Technol., 2007, 18, 67-71.

8 A. de Cuendias, R. Backov, E. Cloutet and H. Cramail, J. Mater. Chem., 2005, 15, 4196-4199.

9 E. Jabbari and M. Khakpour, Biomaterials, 2000, 21, 20732079. 
10 W. H. Guo, W. S. Wang, X. K. Yu, X. M. Peng and N. Y. Ma, RSC Adv., 2015, 5, 80568-80571.

11 G. Crotts and T. G. Park, J. Controlled Release, 1995, 35, 91105.

12 X. Peng and L. Zhang, Langmuir, 2005, 21, 1091-1095.

13 X. W. Lou, L. A. Archer and Z. Yang, Adv. Mater., 2008, 20, 3987-4019.

14 J. Fu, Z. Chen, X. Wu, M. Wang, X. Wang, J. Zhang, J. Zhang and Q. Xu, Chem. Eng. J., 2015, 281, 42-52.

15 X. Zhu, S. Zhang, L. Zhang, H. Liu and J. Hu, RSC Adv., 2016, 6, 58511-58515.

16 J. Li, X. Lai, C. Xing and D. Wang, J. Nanosci. Nanotechnol., 2010, 10, 7707-7710.

17 X. Liu, X. Jin and P. X. Ma, Nat. Mater., 2011, 10, 398-406.

18 X. Liu, Y. Yang and M. W. Urban, Macromol. Rapid Commun., 2017, 38, 1700030.

19 C. Qi, Y.-J. Zhu, B.-Q. Lu, X.-Y. Zhao, J. Zhao and F. Chen, J. Mater. Chem., 2012, 22, 22642-22650.

20 S. Li, L. Nguyen, H. Xiong, M. Wang, T. C. C. Hu, J.-X. She, S. M. Serkiz, G. G. Wicks and W. S. Dynan, Nanotechnol. Biol. Med., 2010, 6, 127-136.

21 Y. Ran, C. Wang, H. Li, J. Zhang, W. Ding and H. Xia, J. Nanosci. Nanotechnol., 2013, 13, 3004-3010.

22 L. Li, J. Ding and J. Xue, Chem. Mater., 2009, 21, 3629-3637. 23 J.-B. Fan, C. Huang, L. Jiang and S. Wang, J. Mater. Chem. B, 2013, 1, 2222-2235.

24 X. D. He, X. W. Ge, H. R. Liu, M. Z. Wang and Z. C. Zhang, Chem. Mater., 2005, 17, 5891-5892.

25 Q. Qian, X. Huang, X. Zhang, Z. Xie and Y. Wang, Angew. Chem., Int. Ed., 2013, 52, 10625-10629.

26 J. Lee, Y. J. Oh, S. K. Lee and K. Y. Lee, J. Controlled Release, 2010, 146, 61-67.

27 X. Gong, W. Wen and P. Sheng, Langmuir, 2009, 25, 70727077.

28 I. G. Loscertales, A. Barrero, I. Guerrero, R. Cortijo, M. Marquez and A. M. Gañán-Calvo, Science, 2002, 295, 1695-1698.
29 J. Melcher and G. Taylor, Annu. Rev. Fluid Mech., 1969, 1, 111-146.

30 M. Cloupeau and B. Prunet-Foch, J. Electrost., 1989, 22, 135159.

31 M. Cloupeau and B. Prunet-Foch, J. Aerosol Sci., 1994, 25, 1021-1036.

32 S. L. Shenoy, W. D. Bates, H. L. Frisch and G. E. Wnek, Polymer, 2005, 46, 3372-3384.

33 P. Fattahi, A. Borhan and M. R. Abidian, Adv. Mater., 2013, 25, 4555-4560.

34 A. Jaworek, Powder Technol., 2007, 176, 18-35.

35 C. Hu, J. Zhao and W. Cui, J. Appl. Polym. Sci., 2013, 128, 3177-3183.

36 S. D. Nath, S. Son, A. Sadiasa, Y. K. Min and B. T. Lee, Int. J. Pharm., 2013, 443, 87-94.

37 D. Fantini, M. Zanetti and L. Costa, Macromol. Rapid Commun., 2006, 27, 2038-2042.

38 N. Bock, M. A. Woodruff, D. W. Hutmacher and T. R. Dargaville, Polymers, 2011, 3, 131.

39 X.-X. Wang, X.-J. Ju, S.-X. Sun, R. Xie, W. Wang, Z. Liu and L.-Y. Chu, RSC Adv., 2015, 5, 34243-34250.

40 M.-W. Chang, E. Stride and M. Edirisinghe, Langmuir, 2010, 26, 5115-5121.

41 K. Pancholi, N. Ahras, E. Stride and M. Edirisinghe, J. Mater. Sci.: Mater. Med., 2009, 20, 917-923.

42 C.-W. Chiu and P.-H. Lin, RSC Adv., 2016, 6, 67204-67211.

43 S. Vlad, C. Ciobanu, M. Butnaru, D. Macocinschi, D. Filip, L. M. Gradinaru and M. Mandru, Dig. J. Nanomater Biostruct., 2011, 6, 643-652.

44 N. Bock, T. R. Dargaville and M. A. Woodruff, Prog. Polym. Sci., 2012, 37, 1510-1551.

45 J. Yao, L. Kuang Lim, J. Xie, J. Hua and C.-H. Wang, J. Aerosol Sci., 2008, 39, 987-1002.

46 N. Arya, S. Chakraborty, N. Dube and D. S. Katti, J. Biomed. Mater. Res., Part B., 2009, 88B, 17-31.

47 S.-W. Choi, Y. Zhang and Y. Xia, Adv. Funct. Mater., 2009, 19, 2943-2949. 